This document is confidential and is proprietary to the American Chemical Society and its authors. Do not copy or disclose without written permission. If you have received this item in error, notify the sender and delete all copies.

\title{
In Vacuo Porphyrin Metalation on Ag(111) via Chemical Vapor Deposition of $\mathrm{Ru}_{3}(\mathrm{CO})_{12}$ : Mechanistic Insights
}

\begin{tabular}{|r|l|}
\hline Journal: & The Journal of Physical Chemistry \\
\hline Manuscript ID & jp-2016-01457v.R1 \\
\hline Manuscript Type: & Article \\
\hline Date Submitted by the Author: & n/a \\
\hline Complete List of Authors: & $\begin{array}{l}\text { Papageorgiou, Anthoula; Technische Universität München, Physik } \\
\text { Department E20 } \\
\text { Diller, Katharina; École polytechnique fédérale de Lausanne, Institute of } \\
\text { Condensed Matter Physics } \\
\text { Fischer, Sybille; Technical University of Munich, Physics Department } \\
\text { Allegretti, Francesco; Technical University of Munich, Physics Department } \\
\text { E20 } \\
\text { Klappenberger, Florian; TU-München, Physics Department } \\
\text { Oh, Seung Cheol; Technische Universität München, } \\
\text { Sağlam, OZzge; Technische Universität München, Physik Department E20 } \\
\text { Reichert, Joachim; TUM, Physik Department E20 } \\
\text { Wiengarten, Alissa; Technical University Munich, } \\
\text { Seufert, Knud; Technische Universität München, Physik Department E20 } \\
\text { Auwärter, Willi; Technische Universität München, Physik Department E20 } \\
\text { Barth, Johannes; TU München, Physics }\end{array}$ \\
\hline
\end{tabular}




\title{
In Vacuo Porphyrin Metalation on Ag(111) via \\ Chemical Vapor Deposition of $\mathrm{Ru}_{3}(\mathrm{CO})_{12}$ :
}

\section{Mechanistic Insights}

\author{
Anthoula C. Papageorgiou, * Katharina Diller, $†$ Sybille Fischer, Francesco Allegretti, \\ Florian Klappenberger, Seung Cheol Oh, Özge Sağlam,ł Joachim Reichert, * Alissa \\ Wiengarten, Knud Seufert, Willi Auwärter, and Johannes V. Barth
}

AUTHOR ADDRESS. Physik-Department E20, Technische Universität München, D-85748

Garching, Germany

\section{AUTHOR INFORMATION}

\section{Corresponding Author}

* Email: a.c.papageorgiou@tum.de (A.C.P.), joachim.reichert@tum.de (J.R.). Telephone numbers: +49-89-289-12618 (A.C.P.), +49-89-289-12618-12443 (J.R.)

\section{Present Addresses}

† Institute of Condensed Matter Physics (ICMP), École Polytechnique Fédérale de Lausanne (EPFL), Station 3, CH-1015 Lausanne, Switzerland. $\$$ Faculty of Engineering and Computer Sciences, Izmir University of Economics, Sakarya Cad.156, Balcova, Izmir, Turkey. 


\begin{abstract}
Porphyrin molecules offer a very stable molecular environment for the incorporation of numerous metal ions inside their cavity, which enables a plethora of applications. The fabrication and characterization of surface confined metal-organic architectures by employing porphyrins are of particular interest. Here we report on a comprehensive study of chemical vapor deposition (CVD) of triruthenium dodecacarbonyl as metal precursor for the on-surface metalation of different porphyrin species with Ru under ultra-high vacuum conditions. By employing synchrotron radiation X-ray photoelectron spectroscopy (XPS), near-edge X-ray absorption fine structure (NEXAFS) and scanning tunneling spectroscopy (STM), we investigated the metalation process and particularly the role of the support: the close packed $\operatorname{Ag}(111)$ surface. It was found that the surface is active in the metalation process under the employed conditions: it decomposes the metal precursor and delivers metal centers to the porphyrin macrocycles. The generality of the metalation process is illustrated for tetraphenylporphyrin, its high temperature derivatives and porphine.
\end{abstract}




\section{INTRODUCTION}

Porphyrin molecules are natural products, with their tetrapyrrole macrocycles providing a well-defined coordination environment for a vast array of reducible metal centers. Biologically important tetrapyrrole macrocycles serve as prosthetic groups in hemoglobin (iron porphyrin) and photosystems (magnesium chlorin), which perform the transport of respiratory gases and energy conversion functions, respectively. These functions depend strongly on the type of hosted metal center.

Porphyrins at interfaces, and in particular their electronic properties and their metalation, have been extensively studied. ${ }^{1-4}$ On surfaces, the porphyrin metalation is most frequently achieved by physical vapor deposition of the desired metal atoms ${ }^{5-7}$ or by capturing surface (ad)atoms, the so-called "self-metalation". ${ }^{8-9}$ In an effort to metalate porphyrins on surfaces using metals with high sublimation temperature (e.g. Ru and Os) without being restricted by the supporting surface, we devised a different approach by employing metal-organic chemical vapor deposition (CVD) to metalate porphyrins on $\operatorname{Ag}(111)$ with trimetal dodecacarbonyls, ${ }^{10-11}$ which are stable in air and thermally decompose on surfaces forming metal clusters. ${ }^{12-13}$ More recently, CVD of metal carbonyl precursors was demonstrated to further provide a route for the on-surface one-dimensional supramolecular assembly of carbonitrile ditopic linker moleculers. ${ }^{14}$

Our earlier multitechnique study showed a self-teminating protocol, whereby following two cycles of exposure of a layer of the cyclodehydrogenated meso-tetraphenylporphyrin $(4,5,6$, 7, Figure 1) to the organometallic precursor molecule $\mathrm{Ru}_{3}(\mathrm{CO})_{12}$ (1) and subsequent annealing to $550 \mathrm{~K}$, all free-base species transformed to ruthenium porphyrins without leaving by-products (such as $\mathrm{CO}$ and excess $\mathrm{Ru}$ ) on the surface. ${ }^{10}$ Here we elucidate the reaction pathway of this metalation method. In particular, we investigate the role of the silver surface in the process. To this end, the thermal chemistry of pristine $\mathrm{Ru}_{3}(\mathrm{CO})_{12}$ molecules 
adsorbed on $\operatorname{Ag}(111)$ and the metalation as a function of the free $\operatorname{Ag}(111)$ surface are investigated. The metalation process was monitored with XPS, while NEXAFS measurements were primarily used to distinguish between 2H-TPP and its planar derivatives. Furthermore, the metalation of pristine $2 \mathrm{H}-\mathrm{TPP}\left(\mathbf{3}\right.$, Figure 1) via $\mathrm{Ru}_{3}(\mathrm{CO})_{12}$ is explored with XPS, NEXAFS and STM. Additional information is provided by the XPS and NEXAFS characterization of a monolayer and multilayers of purchased $\mathrm{Ru}(\mathrm{CO})$-TPP. Finally, we look into the 2H-P (2, Figure 1) metalation with $\mathrm{Ru}_{3}(\mathrm{CO})_{12}$ on $\mathrm{Ag}(111)$ and assess the relevant results in comparison to the respective $\mathrm{Ru}$ metalation of $2 \mathrm{H}-\mathrm{TPP}$ and its planar derivatives. Thus the generality of the introduced CVD approach and the pertaining mechanism is demonstrated.
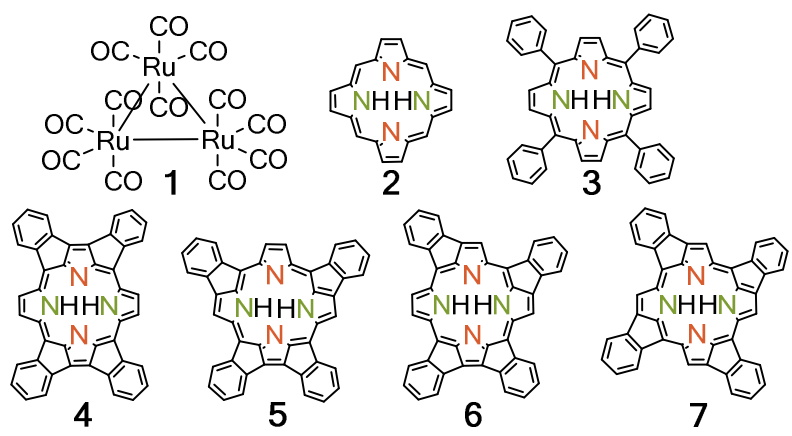

Figure 1. Molecular structures of the $\mathrm{Ru}_{3}(\mathrm{CO})_{12}$ metal precursor 1, porphine (2H-P) 2, mesotetraphenylporphyrin (2H-TPP) $\mathbf{3}$, and the planar $2 \mathrm{H}-\mathrm{TPP}$ derivatives $\mathbf{4}, \mathbf{5}, \mathbf{6}, \mathbf{7}$. Green and orange indicate the aminic and iminic $\mathrm{N}$ sites of the porphyrin macrocycle, respectively.

\section{METHODS}

Clean $\operatorname{Ag}(111)$ single-crystal (Surface Preparation Laboratory) surfaces were prepared by repeated cycles of $\mathrm{Ar}^{+}$sputtering and annealing, as confirmed by XPS (synchrotron measurements at BESSY II) or STM (at TUM). meso-Tetraphenylporphyrin (2H-TPP, 3) (Sigma-Aldrich, $\geq 99 \%$ ) was dosed by organic molecular beam epitaxy (in vacuo sublimation 
temperatures of $600-620 \mathrm{~K})$. The $\mathrm{Ag}(111)$ surface was kept at room temperature (RT) to obtain pristine $2 \mathrm{H}$-TPP layers or at $550 \mathrm{~K}$ to obtain $\sim 1 \mathrm{ML}$ (where $1 \mathrm{ML}$ corresponds to the minimum molecular coverage required to completely cover the silver surface) of the planar 2H-TPP derivatives $(\mathbf{4}, \mathbf{5}, \mathbf{6}, \mathbf{7})$. As in our earlier work, ${ }^{10}$ triruthenium dodecacarbonyl, $\mathbf{1}$, (Aldrich, 99\%) was dosed by exposure of the porphyrin film on $\operatorname{Ag}(111)$ to the vapor of the molecule at RT in a vacuum of $\sim 5 \times 10^{-8}$ mbar (BESSY II) or $\sim 6 \times 10^{-10}$ mbar (TUM). The temperature of the sample was monitored by type $\mathrm{K}$ thermocouple in direct contact with the silver single crystal. The duration of the annealing treatments reported in the results and discussion section below was $\sim 10 \mathrm{~min}$ at the reported temperature.

STM measurements were carried out in two separate custom-made UHV systems with a CreaTec Fischer LT-STM operated at $7 \mathrm{~K}$ and an Aarhus 150 VT-STM operated at 95-300 K. The base pressure during the experiments was $<2 \times 10^{-10}$ mbar in the LT-STM and $<5 \times 10^{-10}$ mbar in the VT-STM. All STM images were recorded in constant-current mode using electrochemically etched tungsten tips. The tunneling bias $\left(V_{\mathrm{s}}\right)$ is applied to the sample. The WsXM program (www.nanotec.es) was used to process the STM images.

Synchrotron XPS and NEXAFS measurements were carried out at the HE-SGM monochromator dipole magnet beamline at the BESSY II synchrotron radiation source in Berlin, which provides light with a linear polarization of $90 \%$. Photoelectron spectra were collected using a Scienta R3000 electron energy analyzer. The angle between the analyzer entrance lens and the incoming photon beam was $45^{\circ}$ in the horizontal plane. All spectra were recorded in normal emission with the sample held approximately at RT. The excitation energies used for the acquisition of the regions of $\mathrm{N} 1 \mathrm{~s}, \mathrm{O} 1 \mathrm{~s}$, and $\mathrm{C} 1 \mathrm{~s} \& \mathrm{Ru} 3 \mathrm{~d}$ spectra were 550, 680, and $435 \mathrm{eV}$, respectively. The binding energy scale of the XP spectra was calibrated against the $\mathrm{Ag} 3 \mathrm{~d}_{5 / 2}$ line at $368.3 \mathrm{eV}$. A polynomial background was subtracted from the raw $\mathrm{N} 1 \mathrm{~s}$ spectra ${ }^{15}$ to compensate the background of $\mathrm{Ag} 3 \mathrm{~d}$ shakeup satellites ${ }^{13,16}$ or 
plasmons, ${ }^{17}$ which is exacerbated by the low signal of $\mathrm{N} 1 \mathrm{~s}$ at submonolayer coverages. The raw data with corrected binding energy scale of all the $\mathrm{N} 1 \mathrm{~s}$ regions presented in this manuscript can be found in the Supporting Information (Figure S1). The reference for the monolayer calibration in the synchrotron measurements is given by the $\mathrm{C} 1 \mathrm{~s}$ and $\mathrm{N}$ 1s signals of a saturated layer of planar 2H-TPP derivatives. Angle-dependent NEXAFS spectra were acquired in partial electron yield mode varying the orientation of the light polarization relative to the surface normal (further details are given in the Supporting Information).

\section{RESULTS AND DISCUSSION}

$\mathbf{R u}_{3}(\mathbf{C O})_{12}$ on $\mathbf{A g}(\mathbf{1 1 1})$. We will first address the adsorption and thermal chemistry of the precursor $\mathrm{Ru}_{3}(\mathrm{CO})_{12}$ on the pristine $\mathrm{Ag}(111)$ without the presence of porphyrins. Directly after deposition at RT (Figure 2a) three main features at $280.7 \mathrm{eV}, 284.8$ and $286.5 \mathrm{eV}$ can be identified in the $\mathrm{C} 1 \mathrm{~s}$ and $\mathrm{Ru} 3 \mathrm{~d}$ core-level region, which are assigned to the $\mathrm{Ru} 3 \mathrm{~d}$ doublet and the CO C 1 s singlet contribution, respectively. ${ }^{18-19}$ Both the $\mathrm{Ru} 3 \mathrm{~d}_{5 / 2}$ and $3 \mathrm{~d}_{3 / 2}$ core levels are split into two components. We attribute this splitting to the inequivalent interaction of the $\mathrm{Ru}$ atoms of the precursor molecule (1) and the $\mathrm{Ag}(111)$ surface. Consistently, a single broad peak originating from $\mathrm{CO}$ is observed in the $\mathrm{O} 1 \mathrm{~s}$ region. Stepwise annealing of the sample to $\sim 500 \mathrm{~K}$ (Figure $2 \mathrm{~b}-\mathrm{d}$ ) leads to a gradual decrease of the $\mathrm{C}$ 1s signal and a shift of the whole spectrum to lower binding energies. After annealing to $540 \mathrm{~K}$ (Figure 2e) no $\mathrm{CO}$ can be detected and the $\mathrm{Ru}$ peaks appear much sharper. Concomitantly, the total amount of ruthenium decreases by a factor of two during the whole annealing process. Together with the $\mathrm{Ru} 3 \mathrm{~d}_{5 / 2}$ binding energy of $280.0 \mathrm{eV}$, which is indicative of $\mathrm{Ru}^{0}$ (see ref. ${ }^{20}$ ) these results show that annealing leads to desorption of the labile CO ligands and the formation of metallic ruthenium. This is consistent with annealing series of $\mathrm{Ru}_{3}(\mathrm{CO})_{12} / \mathrm{Co}(0001)^{18}$ and $\mathrm{Ru}_{3}(\mathrm{CO})_{12} / \mathrm{Au}(111),{ }^{19}$ which show desorption of $\mathrm{CO}$ and a shift to lower binding energies upon annealing. In both cases metallic $\mathrm{Ru}$ is found after the heat treatment. Deviations from 
the reported binding energies of the as-deposited $\mathrm{Ru}_{3}(\mathrm{CO})_{12}$ and in the onset of $\mathrm{CO}$ desorption might be the results of the modified interaction with the surface. In short, we observe that at the temperature applied in our earlier report on the metalation protocol (550 $\mathrm{K}),{ }^{10}$ the Ru precursor $\mathbf{1}$ fully decomposes to metallic $\mathrm{Ru}$ on the $\mathrm{Ag}(111)$ surface.

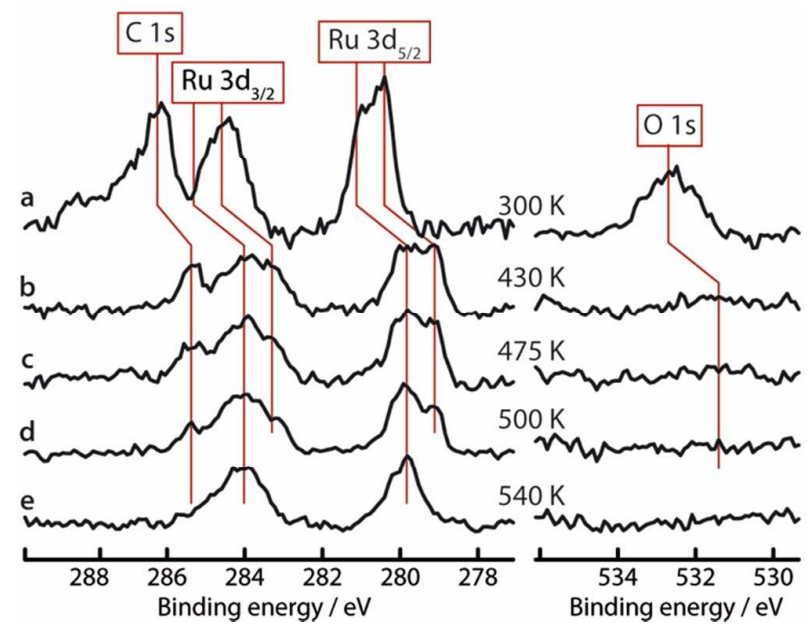

Figure 2. $\mathrm{XP}$ spectra of an annealing series of $\mathrm{Ru}_{3}(\mathrm{CO})_{12}$ on $\mathrm{Ag}(111)$. Directly after deposition three main features are discriminable: The $\mathrm{Ru} 3 \mathrm{~d}$ doublet at $280.7 \mathrm{eV}$ and 284.8 $\mathrm{eV}$, and the $\mathrm{C} 1 \mathrm{~s}$ peak at $286.5 \mathrm{eV}$ due to the $\mathrm{CO}$ ligands. After annealing, $\mathrm{CO}$ desorbs and the ruthenium peaks shift to lower binding energies.

2H-TPP and $\mathrm{Ru}_{3}(\mathrm{CO})_{12}$ on $\mathbf{A g}(\mathbf{1 1 1})$. To elucidate the origin of the self-terminating process we identified in our earlier work, ${ }^{10}$ we examined the metalation as a function of undecorated $\operatorname{Ag}(111)$ areas available to the precursor molecules. To this end surfaces with two different coverages each of pristine $2 \mathrm{H}-\mathrm{TPP}(\mathbf{3})$ and planar $2 \mathrm{H}-\mathrm{TPP}$ derivatives $(\mathbf{4}, \mathbf{5}, \mathbf{6}$, 7) were prepared, resulting in different free silver surface patches. The phenyl legs of pristine 2H-TPP (3) on $\operatorname{Ag}(111)$ are known to tilt with respect to the surface, ${ }^{21}$ which is corroborated by curve-fitting analysis of the angular dependence of $\pi^{*}$ resonances in our angle-resolved NEXAFS measurements (Figure S3a), yielding an average tilt angle of $\sim 45^{\circ}$. Annealing to $550 \mathrm{~K}$ quenches the $\pi^{*}$ resonances of the NEXAFS at $90^{\circ}$ of photon incidence (Figure S3b), 
due to the completion of intramolecular cyclodehydrogenation reactions which yield planar 2H-TPP derivatives $(\mathbf{4}, \mathbf{5}, \mathbf{6}, \mathbf{7}) .{ }^{10,22}$ For $\sim 1$ ML of planar $2 \mathrm{H}$-TPP derivatives, obtained by dosing the molecules on a substrate kept at $550 \mathrm{~K}$ for prolonged time with high flux, the XPS $\mathrm{N}$ 1s region shows two peaks at $397.9 \mathrm{eV}$ (iminic) and $399.6 \mathrm{eV}$ (aminic) (Figure 3a). It can be noted that the aminic nitrogen peak has a slightly higher intensity than the iminic one. This effect was already observed in the first XPS studies of porphyrins and attributed to the presence of a weak satellite of the lower-energy peak which overlaps with that of the aminic nitrogen. ${ }^{23-24}$ The (compared to pristine $2 \mathrm{H}-\mathrm{TPP}$, see below) reduced peak splitting of $1.7 \mathrm{eV}$ is consistent with our previous findings. ${ }^{10}$ After dosing $\mathrm{Ru}_{3}(\mathrm{CO})_{12}$ only a very small amount of $\mathrm{Ru}$ adsorbs (highlighted by the red peak in Figure $3 \mathrm{~b}$ ), whereas in the $\mathrm{C} 1 \mathrm{~s}$ and $\mathrm{N} 1 \mathrm{~s}$ regions no difference can be detected. Consequently, following annealing to $550 \mathrm{~K}$ only a small portion of the porphyrins gets metalated, as evidenced by the appearance of a weak additional component (blue peak in Figure 3c left) at $398.7 \mathrm{eV}$, which is a typical binding energy value for metalloporphyrins, while the signals originating from the nitrogen atoms of the free-base species are slightly reduced. Conversely, for $\sim 0.8 \mathrm{ML}$ of planar 2H-TPP derivatives (Figure 3d), the deposition of the precursor leads to a more pronounced accumulation of $\mathrm{Ru}$ (red peak in Figure $3 \mathrm{e}, 280.6 \mathrm{eV}$ and $281.1 \mathrm{eV})$ and $(\mathrm{CO})(286.5 \mathrm{eV}$, Figure 3e), indicating that $\mathrm{Ru}_{3}(\mathrm{CO})_{12}$ adsorbs on the bare $\operatorname{Ag}(111)$ surface and does not bond to the porphyrin areas at the employed conditions. Subsequent annealing to $550 \mathrm{~K}$ leads to a fully metalated porphyrin layer on the surface, as evidenced by a single peak in the $\mathrm{N} 1 \mathrm{~s}$ spectrum (Figure 3g). Lower annealing temperatures only resulted in incomplete metalation of the overlayer based on the $\mathrm{N}$ 1s spectrum (Figure $3 \mathrm{f}$ ), which clearly exhibits residual contributions of the iminic (orange peak) and aminic (green peak) $\mathrm{N}$ atoms, beside the major component due to the metal coordinated nitrogen (blue peak). As in our earlier report, ${ }^{10}$ the $\mathrm{Ru}$ peak shifts downward (to $279.6 \mathrm{eV}$ ) to a formal $\mathrm{Ru}^{0}$ state, after the metalation. This is in 
agreement with the $\mathrm{Ru}$ oxidation state of pre-synthesized Ru-TPP adsorbed on $\operatorname{Ag}(111)$ (Supporting information and Figure S4). It can also be noticed that the ratio of $\mathrm{Ru} 3 \mathrm{~d}_{5 / 2}$ to $\mathrm{C}$ $1 \mathrm{~s}$ of this surface closely matches the ratio of $\mathrm{Ru} 3 \mathrm{~d}_{5 / 2}$ to $\mathrm{C} 1 \mathrm{~s}$ of Ru-TPP (Supporting information and Figure S4), indicating that all the surface $\mathrm{Ru}$ is engaged in porphyrin macrocycles. Therefore the amount of surface $\mathrm{Ru}$ precursor $\mathbf{1}$ can be controlled by the amount of free silver surface, and, specifically, approximately $20 \%$ of uncovered surface silver ensures the complete metalation of the porphyrin layer without the accumulation of excess Ru. This is in good agreement with a rough calculation based of the 2H-TPP derivatives' $(4,5,6,7)$ molecular surface footprints $\left(\sim 2 \mathrm{~nm}^{2}\right)$ and the precursor $(\mathbf{1})$ molecular area $\left(\sim 1 \mathrm{~nm}^{2}\right)$ : Assuming that the precursor adsorbs only on the free silver surface and that dense packing of the porphyrins and the precursor molecules can be achieved, complete metalation requires $\sim 14 \%$ of free silver surface (this represents, of course, a lower limit given the approximation made). Accordingly the two cycles of exposure and annealing required for the complete, self-limiting metalation protocol in our earlier work are rationalized: in fact, in those porphyrin layers only $\sim 12 \%$ of free silver surface was available. ${ }^{10}$ Excess Ru can accumulate on the surface with a single exposure, if less than $\sim 80 \%$ of the Ag surface is covered. 


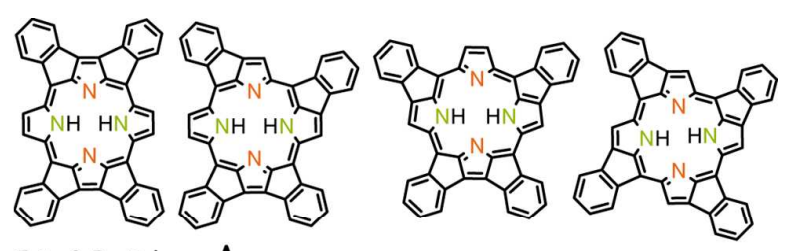

C 1s \& Ru 3d

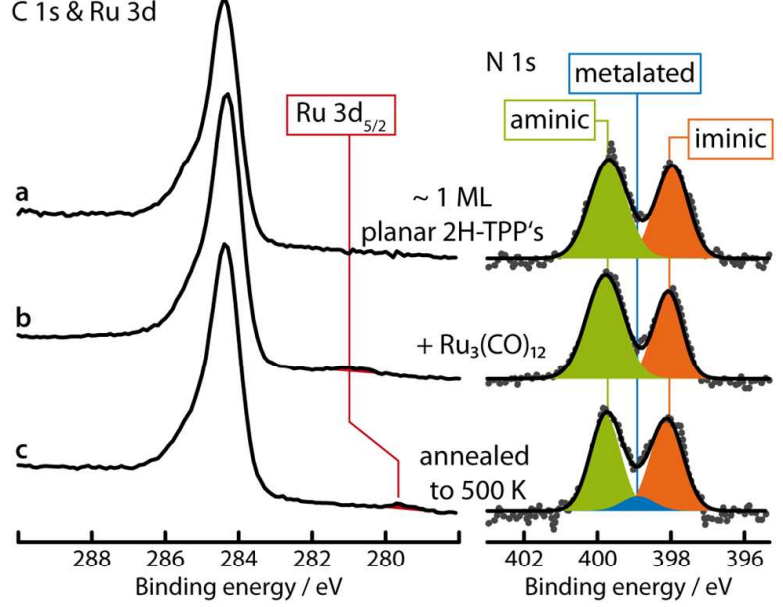

C 1s \& Ru 3d
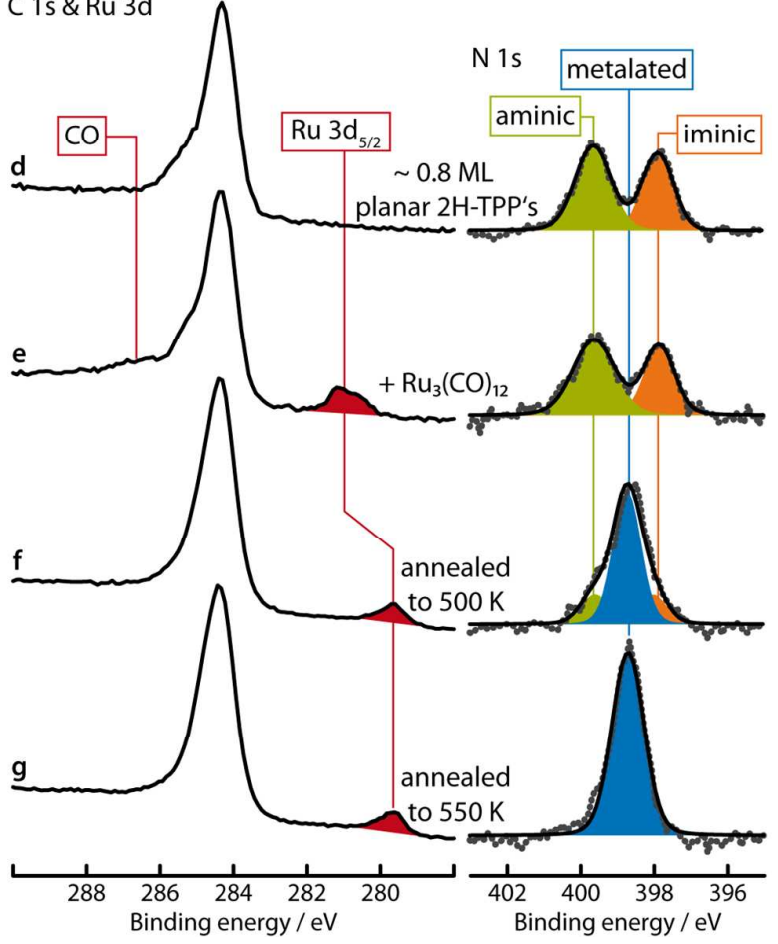

Figure 3: XP spectra of the $\mathrm{C} 1 \mathrm{~s}$ and $\mathrm{Ru} 3 \mathrm{~d}$ (left) and $\mathrm{N}$ 1s (right) regions corresponding to: (a) $\sim 1$ ML of planar 2H-TPP derivatives on $\mathrm{Ag}(111)$ (b) after exposure to $\mathrm{Ru}_{3}(\mathrm{CO})_{12}$ and after (c) annealing to $500 \mathrm{~K}$ and (d) $\sim 0.8 \mathrm{ML}$ of planar 2H-TPP derivatives on $\operatorname{Ag}(111)$ (e) after exposure to $\mathrm{Ru}_{3}(\mathrm{CO})_{12}$ and (f) after annealing to $500 \mathrm{~K}$ and (g) $550 \mathrm{~K}$. 
Next, the coverage-dependent metalation of the pristine $2 \mathrm{H}-\mathrm{TPP}$ on $\operatorname{Ag}(111)$ is presented. To look into the adsorption behavior of the precursor on the 2H-TPP layer, a sample with a 2H-TPP coverage of $\sim 1.3 \mathrm{ML}$ was deposited on $\operatorname{Ag}(111)$. 2H-TPP adsorbed on $\operatorname{Ag}(111)$ forms close-packed islands (Figure 5a), ${ }^{25}$ so that it can be assumed that at this coverage no bare silver is available. The XPS N 1s region shows two peaks at $398.1 \mathrm{eV}$ (iminic) and $400.1 \mathrm{eV}$ (aminic), i.e., a peak splitting of $2.0 \mathrm{eV}$ (Figure S5a right), which is in full agreement with literature data. ${ }^{26-28}$ After exposing this layer to the $\mathrm{Ru}_{3}(\mathrm{CO})_{12}$ vapor no $\mathrm{Ru}$ signal is detected, nor any change of the C 1s and N 1s spectra (Figure S5b), indicating that the precursor molecules have a negligible sticking coefficient to the porphyrins at RT in UHV. Consequently, after annealing to $530 \mathrm{~K}$, no indication of metalation is found (Figure S5c).

As it is now evident that the precursor does not adsorb (nor dissociates) on top of the $2 \mathrm{H}$ TPP at RT in UHV, we explored the metalation on a submonolayer coverage $(\sim 0.4 \mathrm{ML})$ of 2H-TPP on $\mathrm{Ag}(111)$ (Figure 4a). Dosing $\mathrm{Ru}_{3}(\mathrm{CO})_{12}$ onto this surface hardly influences the $\mathrm{N}$ 1s region (Figure $4 \mathrm{~b}$ right). In the $\mathrm{C} 1 \mathrm{~s}$ region, however, additional peaks, which originate from $\mathrm{Ru} 3 \mathrm{~d}_{5 / 2}(280.5 \mathrm{eV}$ and $281.0 \mathrm{eV})$ and $\mathrm{CO}(286.4 \mathrm{eV})$ (Figure $4 \mathrm{~b}$ left), are clearly discernible. The intensity of the $\mathrm{C} 1 \mathrm{~s}$ porphyrin peak at $284.8 \mathrm{eV}$ appears to be higher than before, due to the overlap with the $\mathrm{Ru} 3 \mathrm{~d}_{3 / 2}$ peaks. O $1 \mathrm{~s}$ measurements (not displayed) confirm the presence of oxygen on the sample. Annealing to $500 \mathrm{~K}$ causes the desorption of $\mathrm{CO}$ (Figure 4c left) and a distinct downward shift of the Ru peaks. In the $\mathrm{N}$ 1s region, the chemical state of Ru coordinated $\mathrm{N}$ appears at $398.8 \mathrm{eV}$ (blue peak in Figure 4c right). 


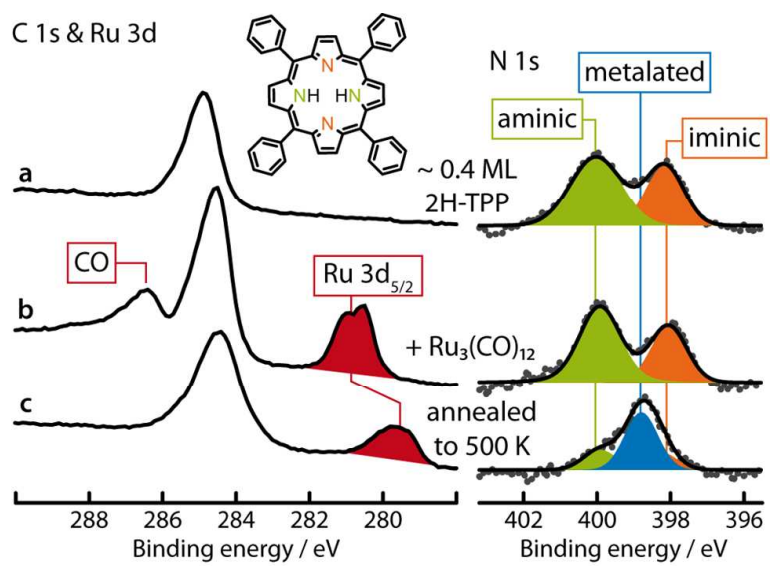

Figure 4. XP spectra of the metalation of $2 \mathrm{H}-\mathrm{TPP}$ on $\operatorname{Ag}(111)$ with $\mathrm{Ru}_{3}(\mathrm{CO})_{12}$. (a) On the surface with a submonolayer coverage of $2 \mathrm{H}-\mathrm{TPP}$ (b) a large amount of the precursor can accumulate ( $\mathrm{Ru} 3 \mathrm{~d}_{5 / 2}$ peak colored red). (c) After annealing to $500 \mathrm{~K}$, the CO ligands desorb, the two $\mathrm{N}$ 1s peaks originating from the iminic (orange) and aminic (green) nitrogen species are quenched and a new peak (blue) emerges, which is assigned to the nitrogen in $\mathrm{Ru}$ porphyrins.

While at this temperature the metalation is not yet complete, the corresponding NEXAFS C K-edge spectra (Figure S3c) have changed substantially compared to the data of the untreated sample (Figure S3a). All curves appear broadened and the intensity of the $90^{\circ}$-curve in the $\pi$ region is diminished, which indicates a more planar adsorption geometry. This broadening and angular dependence is not characteristic of the corresponding pristine $\mathrm{Ru}-$ TPP spectrum (Figure S3e), which reveals a saddle-shape conformation of the macrocycle and strongly rotated phenyl legs with respect to the surface plane. The origin of these changes might be the stronger interaction with the Ru modified silver substrate, but they might also originate from cyclodehydrogenation side reactions, which can have a lower activation barrier in the presence of surface ruthenium, as also observed in the presence of surface osmium. $^{11}$ 
To clarify this point, complementary STM measurements were performed. Figure 5a shows a typical image of an island of 2H-TPP forming on the $\operatorname{Ag}(111)$ surface. Individual 2H-TPP molecules can be resolved (examples outlined in blue in Figure 5a,b) with submolecular resolution: the four protrusions in the periphery correspond to the tilted phenyl moieties, whereas the central ring represents the macrocycle. ${ }^{21}$ The $2 \mathrm{H}-\mathrm{TPP}$ molecules self-assemble in close packed islands stabilized by T-type interactions between the phenyl legs. ${ }^{29-30}$ The STM appearance of the surface depicted in Figure 5a after exposure to $\mathrm{Ru}_{3}(\mathrm{CO})_{12}$ and annealing to $463 \mathrm{~K}$ is shown in Figure 5 b. Here, intact $2 \mathrm{H}$-TPP molecules can be identified (examples circled in blue solid line) as well as the corresponding Ru-TPP molecule (one such molecule circled in blue dashed line). However the outline of many molecules has changed (outlined in green in Figure 5b), which signifies cyclodehydrogenation reactions between phenyl legs and the macrocycle. ${ }^{31}$ The intramolecular cyclodehydrogenation reactions result in the phenyl substituents being co-planar and therefore do not allow the T-type interactions that drive the self-assembly observed in Figure 5a. This leads to an evident loss of order in the molecular assembly. Importantly, it is further noted that this loss of order is not associated with the Ru metalation, as Ru-TPP also forms the same structure as that observed in Figure $5 \mathrm{a}^{31}$ A small portion of the surface molecules exhibits a bright protrusion (e.g. circled in dashed lines in Figure $5 b$ ) in the middle of the macrocycle ring, indicative of the insertion of $\mathrm{Ru}^{10}$ After further annealing of this surface to $493 \mathrm{~K}$, we observe that the fraction of metalated porphyrins has increased. At the same time, the majority of the porphyrins has completed all the possible intramolecular cyclodehydrogenation reactions and the surface molecular species are mainly the 2H-TPP derivatives 4, 5, 6, 7 (Figure 1) and their Ru metalated counterparts. These are identified by their match to the molecular structure outline and the apparent height of their center (depression or protrusion). It is worth noting that the same cyclodehydrogenation reaction requires an annealing treatment of $\sim 550 \mathrm{~K}$ on the bare 
$\operatorname{Ag}(111)$ surface, ${ }^{10,31-32}$ but only $\sim 423 \mathrm{~K}$ when the surface has been exposed to $\mathrm{Os}_{3}(\mathrm{CO})_{12}{ }^{11}$

We therefore conclude that the presence of surface $\mathrm{Ru}$ promotes these cyclodehydrogenation reactions, albeit less efficiently than the presence of surface Os.

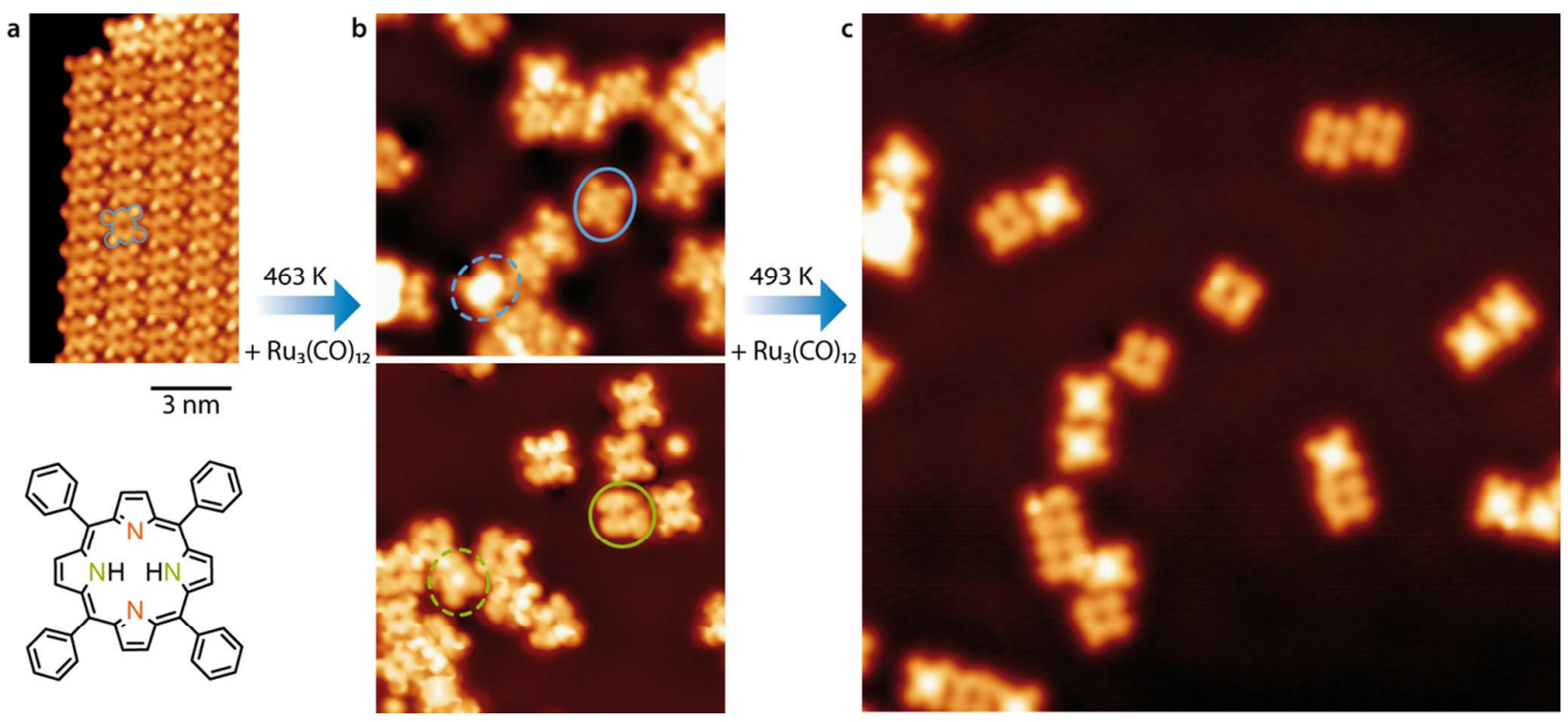

Figure 5. STM micrographs in the same scale of the reactants and products of the reaction of 2H-TPP (left) with $\mathrm{Ru}_{3}(\mathrm{CO})_{12}$ on $\mathrm{Ag}(111)$. (a) An island of $2 \mathrm{H}-\mathrm{TPP}$ molecules $(T=7 \mathrm{~K}, I=$ $\left.0.14 \mathrm{nA}, V_{\mathrm{s}}=-0.43 \mathrm{~V}\right)$. (b) The same surface after exposure to $\mathrm{Ru}_{3}(\mathrm{CO})_{12}$ and annealing to $463 \mathrm{~K}\left(T=7 \mathrm{~K}, I=0.45 \mathrm{nA}, V_{\mathrm{s}}=-0.50 \mathrm{~V}\right)$ and (c) after further annealing to $493 \mathrm{~K}(T=7 \mathrm{~K}$, $\left.I=0.13 \mathrm{nA}, V_{\mathrm{s}}=-0.50 \mathrm{~V}\right)$.

2H-P on Ag(111). In a similar fashion we investigated the metalation of $2 \mathrm{H}-\mathrm{P}$. Similar to 2H-TPP and its derivatives, no metalation can be achieved without uncovered silver, because the $\mathrm{Ru}_{3}(\mathrm{CO})_{12}$ molecules do not adsorb on top of the porphine layer (not shown) under the employed conditions. For coverages below one monolayer, the $\mathrm{N}$ 1s data show that full metalation is possible (Figure 6e). Of special interest is hereby the $\mathrm{C} 1 \mathrm{~s}$ region. For 2H-TPP the large number of inequivalent carbon atoms prevents a straightforward interpretation of the spectra. Instead, $2 \mathrm{H}-\mathrm{P}$ contains only five inequivalent carbon species, ${ }^{33}$ implying that changes upon annealing are more clearly discernible. Indeed, during the annealing series, the 
C 1s core-level line undergoes a visible transformation. After deposition of the Ru precursor and annealing to $470 \mathrm{~K}$ additional shoulders appear on both sides of the broad original peak (Figure 6c). Notably, the fully metalated Ru-P layer exhibits two sharp peaks which are reminiscent of the $\mathrm{C} 1$ s core-level spectra of $2 \mathrm{H}-\mathrm{P}$ adsorbed on $\mathrm{Cu}(111)^{33}$ and $\mathrm{Cu}-\mathrm{P} / \mathrm{Cu}(111)$ (Figure S6). The second peak appears at lower binding energies, which is typical for a metalcoordinated carbon species. ${ }^{34}$ These results might suggest that after desorption of CO, mobile $\mathrm{Ru}$ adatoms may diffuse below the porphine molecules, in such a way that we effectively observe a Ru-P/Ru system. An alternative scenario is the coordination of $\mathrm{Ru}-\mathrm{P}$ to ruthenium to form chains, resulting in an organometallic surface network. Additionally, the presence of the $\mathrm{Ru}$ on the surface appears to prevent a desorption of the molecules, as it was found that the coverage of $2 \mathrm{H}-\mathrm{P}$ on $\mathrm{Ag}(111)$ gradually decreases upon annealing (desorption rate at 533 $\left.\mathrm{K}: \sim 3 \% \mathrm{ML} \cdot \mathrm{min}^{-1}\right)^{35}$ which is not the case here.

The C K-edge NEXAFS spectra corresponding to the sample annealed to $505 \mathrm{~K}$ (Fig. S3d) clearly correspond to that of a metalloporphine. ${ }^{36-37}$ In contrast to the C K-edge NEXAFS spectrum of the Ru metalated planar TPP derivatives on $\operatorname{Ag}(111)$ discussed in the section before and the $2 \mathrm{H}-\mathrm{P}$ homocoupling reaction products on $\operatorname{Ag}(111),{ }^{35}$ the respective Ru-P NEXAFS spectrum is only marginally broadened. This suggests that the broadening of the NEXAFS spectra can be associated with extending the $\pi$ conjugation of the molecule either via cyclodehydrogenations or dimerization, rather than with the metalation process itself. STM inspection of a similarly prepared surface (Figure 6f) revealed the formation of irregular chains (two examples outlined by dotted green lines in Figure 6f), which were found to be stable for imaging up to room temperature. In comparison, individual $2 \mathrm{H}-\mathrm{P}$ molecules on $\operatorname{Ag}(111)$ are too mobile to be imaged under similar tunneling conditions even at $\sim 113 \mathrm{~K}$. Only a few free base species, characterized by an asymmetric ring with a characteristic depression, ${ }^{38}$ can be identified within these chains (circled in blue), suggesting that the 
majority of molecules is metalated. The STM image does not allow to unambiguously identify the monomers within the chains, therefore the intermolecular distances cannot be deduced. However, based on the corresponding NEXAFS spectroscopic signature and the changes in the C 1s XPS region discussed above we can propose that these chains are stabilized by interactions between $\mathrm{Ru}$ atoms and porphine molecules, rather than by intermolecular C-C couplings observed in our earlier work. ${ }^{35}$
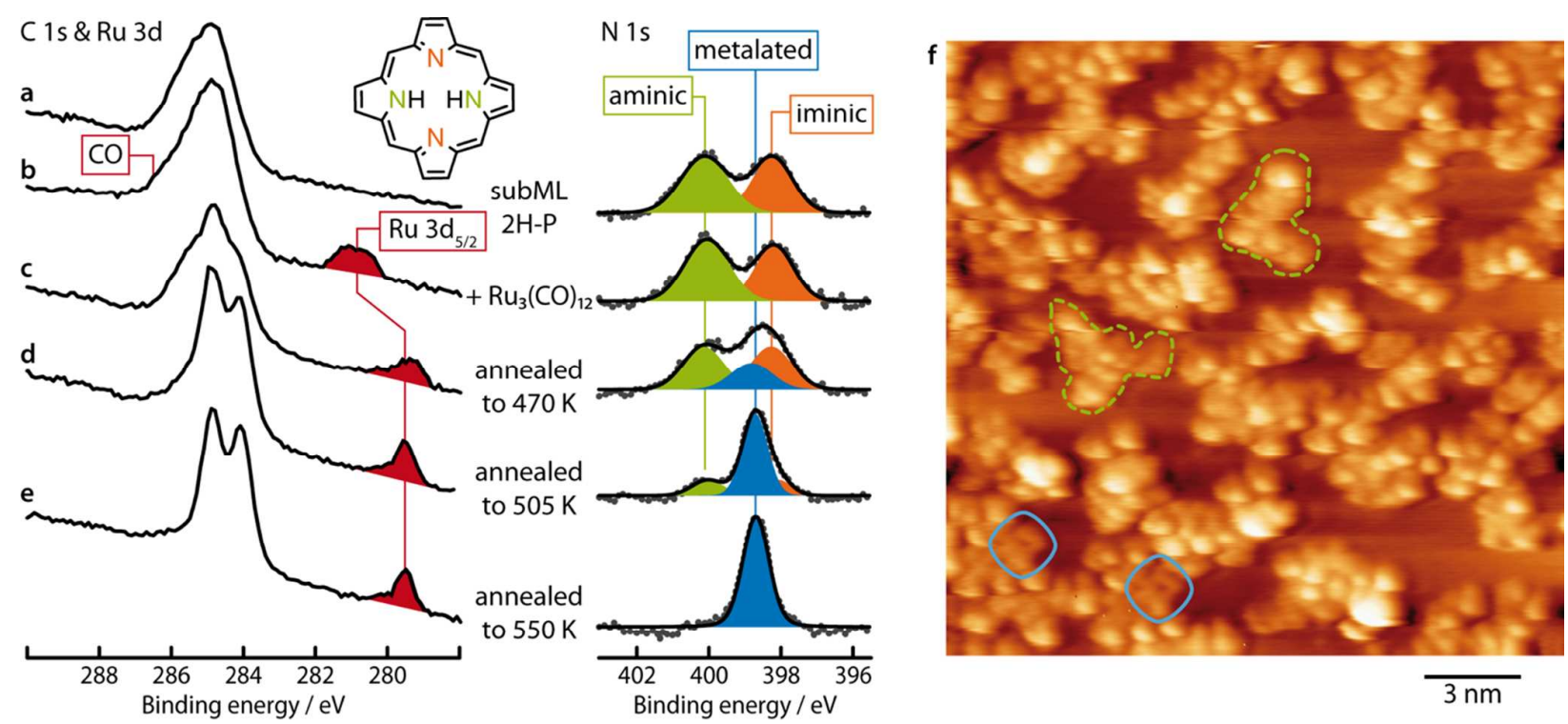

Figure 6. Metalation of $2 \mathrm{H}-\mathrm{P} / \mathrm{Ag}(111)$ with $\mathrm{Ru}_{3}(\mathrm{CO})_{12}$. (a-e) Sequential spectra for the $\mathrm{C} 1 \mathrm{~s}$ and $\mathrm{N} 1 \mathrm{~s}$ core levels. The $\mathrm{Ru} 3 \mathrm{~d}_{5 / 2}$ peak is colored red. Annealing leads to the formation of Ru-P, as indicated by the growth of a new peak (blue, $398.8 \mathrm{eV}$ ) in the N 1s spectra. (f) STM $\left(T=95 \mathrm{~K}, I=0.05 \mathrm{nA}, V_{\mathrm{s}}=-1.07 \mathrm{~V}\right)$ image of Ru-P on $\mathrm{Ag}(111)$ after dosing $\mathrm{Ru}_{3}(\mathrm{CO})_{12}$ and annealing to $500 \mathrm{~K}$.

\section{CONCLUSIONS}

Our key finding are summarized in Figure 7. We have shown that metalation by metalorganic CVD is possible for $2 \mathrm{H}-\mathrm{TPP}$, its high-temperature planar cyclodehydrogenated $2 \mathrm{H}$ TPP derivatives and 2H-P. For all three compounds annealing temperatures of $550 \mathrm{~K}$ were required for a complete metalation. Coverage dependent measurements reveal that the crucial 
point is the amount of bare silver available, as the $\mathrm{Ru}_{3}(\mathrm{CO})_{12}$ precursor neither adsorbs nor transforms on top of the molecules under UHV at RT. For all coverages of free-base porphyrins, as well as for the pure $\mathrm{Ru}_{3}(\mathrm{CO})_{12}$ compound, no carbon monoxide could be detected after annealing to $550 \mathrm{~K}$. Excess Ru can accumulate on the surface depending on the surface concentration of adsorbed $\mathrm{Ru}$ precursor. The latter can be controlled either by the dosing time or by the free silver surface. Moreover, the critical role of the silver surface in the CVD metalation process was elucidated. The porphyrin metalation temperatures coincide with the formation of adsorbed metallic $\mathrm{Ru}$. Therefore a reaction mechanism can be confidently proposed: the Ru precursor adsorbs on the bare Ag surface, where it thermally decomposes resulting in reactive $\mathrm{Ru}$ atoms which metalate surface porphyrin species. As the sticking of $\mathrm{Ru}_{3}(\mathrm{CO})_{12}$ is limited to the free silver at RT under UHV, higher porphyrin coverages mean that the accumulation of $\mathrm{Ru}$ under these conditions and consequently the reaction can become self-limiting. This constitutes a big advantage over the use of electron beam evaporators for the deposition of the metal atoms, for which the dosage of the exact metal amount is an additional challenge. The XPS and NEXAFS data of pre-synthesized RuTPP point to a saddle-shaped molecular conformation on $\operatorname{Ag}(111)$, as well as to a reduction of the formal +2 state of the ruthenium in the free porphyrin to $\mathrm{Ru}^{0}$ in the molecules directly in contact with the silver substrate, which presumably reflects charge transfer between substrate and molecules. The same result is found for in vacuo metalated porphyrins, indicating that the apparent oxidation state is not drastically influenced by the height of the molecules above the substrate, which can be expected to be different for the pristine TPP species with tilted phenyl substituents on the one hand, and the planar 2H-TPP derivatives and $2 \mathrm{H}-\mathrm{P}$ on the other hand. Finally, we observed that surface Ru additionally interacts with the peripheral carbon atoms of the porphyrin molecules. For the $2 \mathrm{H}-\mathrm{TPP}$, it lowers the 
activation barrier of the intramolecular cyclodehydrogenation reactions, whereas for the $2 \mathrm{H}$ $\mathrm{P}$, it likely induces the formation of metal-organic chains.

1

2

3

4

5

6

7

8

9

10

11

12

13

14

15

16

17

18

19

20

21

22

23

24

25

26

27

28

29

30

31

32

33

34

35

36

37

38

39

40

41

42

43

44

45

46

47

48

49

50

51

52

53

54

55

56

57

58

59

60 
a

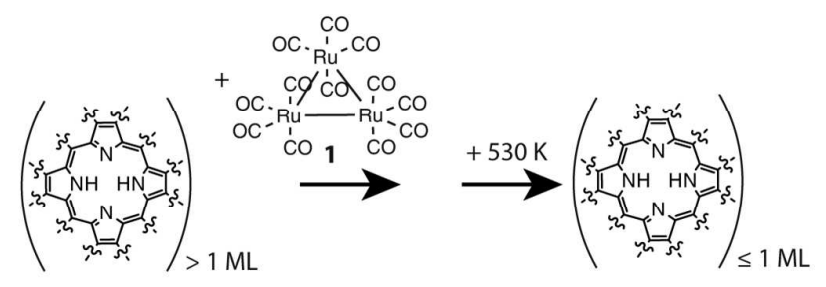

b
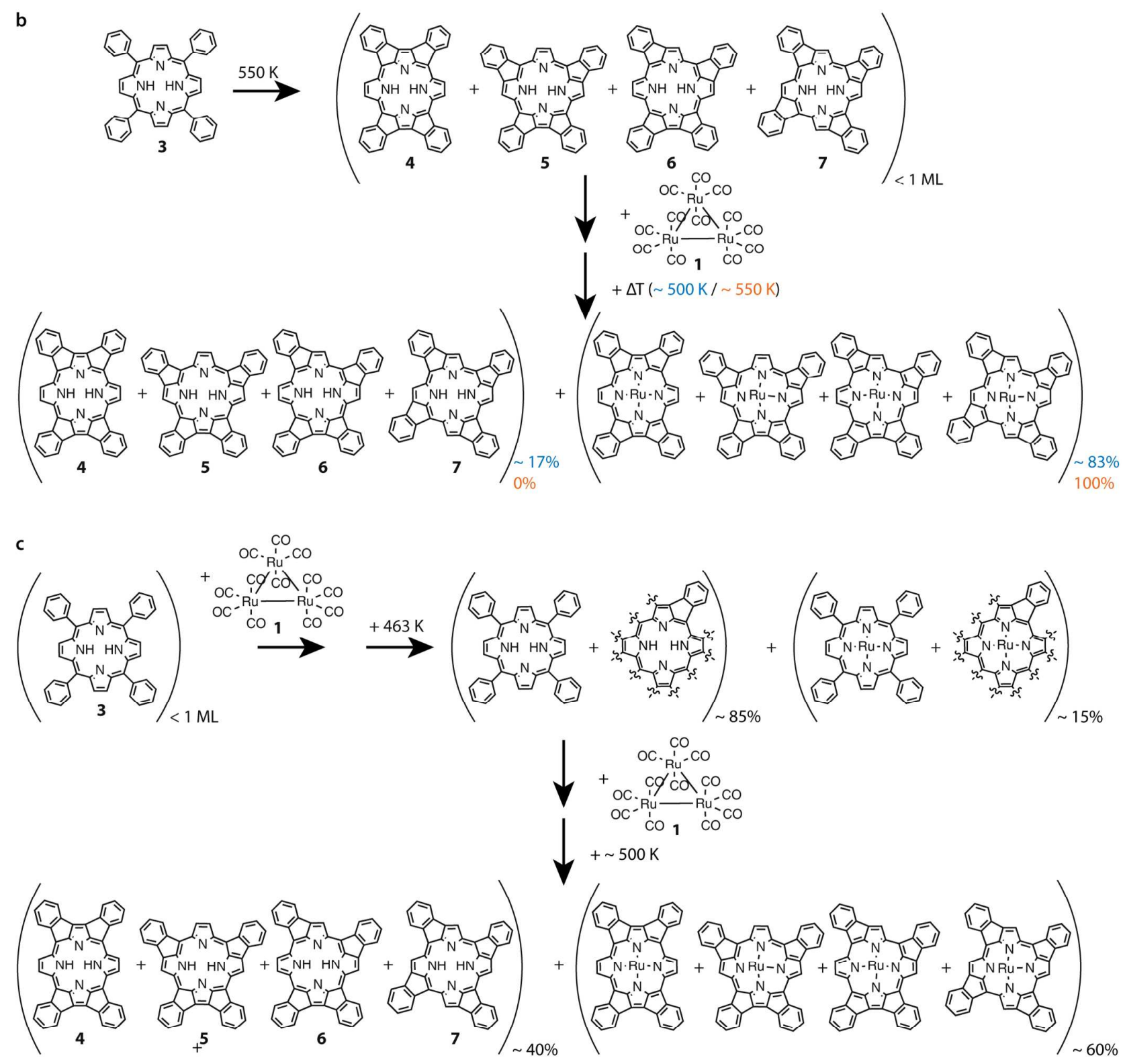

d

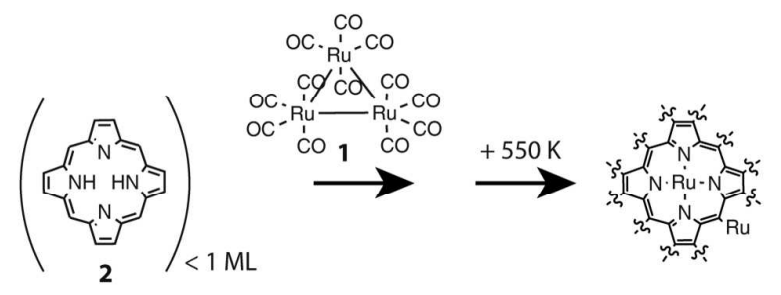


Figure 7. Summary of surface reactions observed here between porphyrin molecules supported on $\operatorname{Ag}(111)$ and the metal precursor 1 under UHV conditions. (a) For porphyrin coverages above a monolayer no reaction is observed. (b) The 2 H-TPP derivatives $\mathbf{4 , 5}, \mathbf{6}, \mathbf{7}$ metalate after heating to $500 \mathrm{~K}$ and is completed after heating to $550 \mathrm{~K}$. (c) In 2H-TPP both metalation and cyclodehydrogenations occur after heating to $463 \mathrm{~K}$. All possible $2 \mathrm{H}-\mathrm{TPP}$ cyclodehydrogenations are completed after heating to $500 \mathrm{~K}$. (d) $2 \mathrm{H}-\mathrm{P}$ both metalates and coordinates to $\mathrm{Ru}$ atoms.

\section{ASSOCIATED CONTENT}

Supporting Information. Raw data of N 1s spectra; experimental: NEXAFS; NEXAFS C K-edge spectra; XPS and NEXAFS of Ru-TPP on Ag(111); XP spectra of Ru-TPP on $\operatorname{Ag}(111)$; absence of $\mathrm{Ru}_{3}(\mathrm{CO})_{12}$ on multilayer $2 \mathrm{H}-\mathrm{TPP}$ on $\mathrm{Ag}(111)$ : XP spectra; C 1s of $2 \mathrm{H}-\mathrm{P}$ and $\mathrm{Cu}-\mathrm{P}$ on $\mathrm{Cu}(111)$. This material is available free of charge via the Internet at http://pubs.acs.org.

\section{Notes}

The authors declare no competing financial interests.

\section{ACKNOWLEDGMENT}

We thank Helmholtz-Zentrum Berlin (HZB) for the allocation of synchrotron radiation beamtime and financial support. The authors thank Peter Feulner for assistance during the synchrotron experiments, and Alexei Nefedov and Christof Wöll for access to the HE-SGM end station. This work was supported by the EU FP7 program through the European Research Council Advanced Grant MolArt (J.V.B, no. 247299) and the Marie Curie Fellowships NASUMECA (A.C.P., no. 274842) and NANOULOP (Ö.S., no. 302157). Further funding was provided by the Munich-Centre for Advanced Photonics (project B.1.3), the TUM-IAS 
(W.A.) and the International Max Planck Research School of Advanced Photon Science (IMPRS-APS) (A.W.).

\section{REFERENCES}

1. Auwärter, W.; Écija, D.; Klappenberger, F.; Barth, J. V., Porphyrins at Interfaces. Nat. Chem. 2015, 7, 105-120.

2. Gottfried, J. M., Surface Chemistry of Porphyrins and Phthalocyanines. Surf. Sci. Rep. 2015, 70, 259-379.

3. Marbach, H., Surface-Mediated in Situ Metalation of Porphyrins at the Solid-Vacuum Interface. Acc. Chem. Res. 2015, 48, 2649-2658.

4. Diller, K.; Papageorgiou, A. C.; Klappenberger, F.; Allegretti, F.; Barth, J. V.; Auwärter, W., In Vacuo Interfacial Tetrapyrrole Metallation. Chem. Soc. Rev. 2016, 45, 1629-1656.

5. Weber-Bargioni, A.; Reichert, J.; Seitsonen, A. P.; Auwärter, W.; Schiffrin, A.; Barth, J. V., Interaction of Cerium Atoms with Surface-Anchored Porphyrin Molecules. J. Phys. Chem. C 2008, 112, 3453-3455.

6. Auwärter, W.; Weber-Bargioni, A.; Brink, S.; Riemann, A.; Schiffrin, A.; Ruben, M.; Barth, J. V., Controlled Metalation of Self-Assembled Porphyrin Nanoarrays in Two Dimensions. ChemPhysChem 2007, 8, 250-254.

7. Gottfried, J. M.; Flechtner, K.; Kretschmann, A.; Lukasczyk, T.; Steinrück, H.-P., Direct Synthesis of a Metalloporphyrin Complex on a Surface. J. Am. Chem. Soc. 2006, 128, $5644-5645$. 
8. Diller, K.; Klappenberger, F.; Marschall, M.; Hermann, K.; Nefedov, A.; Wöll, C.; Barth, J. V., Self-Metalation of 2H-tetraphenylporphyrin on $\mathrm{Cu}(111)$ : An X-Ray Spectroscopy Study. J. Chem. Phys. 2012, 136, 014705-13.

9. Goldoni, A.; Pignedoli, C. A.; Di Santo, G.; Castellarin-Cudia, C.; Magnano, E.; Bondino, F.; Verdini, A.; Passerone, D., Room Temperature Metalation of 2H-TPP Monolayer on Iron and Nickel Surfaces by Picking up Substrate Metal Atoms. ACS Nano 2012, 6, 10800-10807.

10. Papageorgiou, A. C.; Fischer, S.; Oh, S. C.; Sağlam, Ö.; Reichert, J.; Wiengarten, A.; Seufert, K.; Vijayaraghavan, S.; Écija, D.; Auwärter, W., et al., Self-Terminating Protocol for an Interfacial Complexation Reaction in Vacuo by Metal-Organic Chemical Vapor Deposition. ACS Nano 2013, 7, 4520-4526.

11. Sağlam, Ö.; Yetik, G.; Reichert, J.; Barth, J. V.; Papageorgiou, A. C., On-Surface Reaction of Tetraphenylporphyrins with $\mathrm{Os}_{3}(\mathrm{CO})_{12}$ Precursors and Os Clusters: A Scanning Tunnelling Microscopy Investigation. Surf. Sci. 2016, 646, 26-30.

12. Kulkarni, A.; Lobo-Lapidus, R. J.; Gates, B. C., Metal Clusters on Supports: Synthesis, Structure, Reactivity, and Catalytic Properties. Chem. Commun. 2010, 46, 59976015.

13. Pollak, R. A.; Ley, L.; McFeely, F. R.; Kowalczyk, S. P.; Shirley, D. A., Characteristic Energy Loss Structure of Solids from X-Ray Photoemission Spectra. J. Electron Spectrosc. Relat. Phenom. 1974, 3, 381-398.

14. Anderson, A. E.; Grillo, F.; Larrea, C. R.; Seljamäe-Green, R. T.; Früchtl, H. A.; Baddeley, C. J., Metallosupramolecular Assembly of $\mathrm{Cr}$ and $p$-Terphenyldinitrile by Dissociation of Metal Carbonyls on Au(111). J. Phys. Chem. C 2016, 120, 1049-1055. 
15. Diller, K. Free-Base and Metalated Porphyrins on Metal Surfaces - a Systematic XRay Spectroscopy and Density Functional Theory Investigation. Technische Universität München, München, 2013.

16. Mårtensson, N.; Nyholm, R.; Johansson, B., New Observation of Two-Hole CoreLevel Satellites in Copper, Silver, and Gold. Phys. Rev. B 1984, 29, 4800-4802.

17. Stadler, C.; Hansen, S.; Pollinger, F.; Kumpf, C.; Umbach, E.; Lee, T. L.; Zegenhagen, J., Structural Investigation of the Adsorption of $\mathrm{SnPc}$ on $\mathrm{Ag}(111)$ Using Normal-Incidence X-Ray Standing Waves. Phys. Rev. B 2006, 74, 035404.

18. Vaari, J.; Lahtinen, J.; Hautojärvi, P., A Bimetallic Ru-Co Surface Prepared by $\mathrm{Ru}_{3}(\mathrm{CO})_{12}$ Adsorption on Co(0001). Surf. Sci. 1996, 346, 11-17.

19. Cai, T.; Song, Z.; Chang, Z.; Liu, G.; Rodriguez, J. A.; Hrbek, J., Ru Nanoclusters Prepared by $\mathrm{Ru}_{3}(\mathrm{CO})_{12}$ Deposition on $\mathrm{Au}\left(\begin{array}{lll}1 & 1 & 1\end{array}\right)$. Surf. Sci. 2003, 538, 76-88.

20. Wagner, C. D.; Riggs, W. M.; Davis, L. E.; Moulder, J. F.; Muilenberg, G. E., Handbook of X-Ray Photoelectron Spectroscopy : A Reference Book of Standard Data for Use in X-Ray Photoelectron Spectroscopy; Perkin-Elmer Corporation: U.S.A., 1979.

21. Auwärter, W.; Seufert, K.; Bischoff, F.; Écija, D.; Vijayaraghavan, S.; Joshi, S.; Klappenberger, F.; Samudrala, N.; Barth, J. V., A Surface-Anchored Molecular Four-Level Conductance Switch Based on Single Proton Transfer. Nat. Nanotechnol. 2012, 7, 41-46.

22. Di Santo, G.; Sfiligoj, C.; Castellarin-Cudia, C.; Verdini, A.; Cossaro, A.; Morgante, A.; Floreano, L.; Goldoni, A., Changes of the Molecule-Substrate Interaction Upon Metal Inclusion into a Porphyrin. Chem. - Eur. J. 2012, 18, 12619-12623. 
23. Karweik, D. H.; Winograd, N., Nitrogen Charge Distributions in Free-Base Porphyrins, Metalloporphyrins, and Their Reduced Analogs Observed by X-Ray Photoelectron Spectroscopy. Inorg. Chem. 1976, 15, 2336-2342.

24. Niwa, Y.; Kobayashi, H.; Tsuchiya, T., X-Ray Photoelectron Spectroscopy of Tetraphenylporphin and Phthalocyanine. J. Chem. Phys. 1974, 60, 799-807.

25. Rojas, G.; Simpson, S.; Chen, X.; Kunkel, D. A.; Nitz, J.; Xiao, J.; Dowben, P. A.; Zurek, E.; Enders, A., Surface State Engineering of Molecule-Molecule Interactions. Phys. Chem. Chem. Phys. 2012, 14, 4971-4976.

26. Buchner, F.; Flechtner, K.; Bai, Y.; Zillner, E.; Kellner, I.; Steinrück, H.-P.; Marbach, H.; Gottfried, J. M., Coordination of Iron Atoms by Tetraphenylporphyrin Monolayers and Multilayers on $\operatorname{Ag}(111)$ and Formation of Iron-Tetraphenylporphyrin. J. Phys. Chem. C 2008, $112,15458-15465$.

27. Gottfried, J. M.; Flechtner, K.; Kretschmann, A.; Lukasczyk, T.; Steinrück, H.-P., Direct Synthesis of a Metalloporphyrin Complex on a Surface. J. Am. Chem. Soc. 2006, 128, $5644-5645$.

28. Shubina, T. E.; Marbach, H.; Flechtner, K.; Kretschmann, A.; Jux, N.; Buchner, F.; Steinrück, H.-P.; Clark, T.; Gottfried, J. M., Principle and Mechanism of Direct Porphyrin Metalation: Joint Experimental and Theoretical Investigation. J. Am. Chem. Soc. 2007, 129, 9476-9483.

29. Auwärter, W.; Seufert, K.; Klappenberger, F.; Reichert, J.; Weber-Bargioni, A.; Verdini, A.; Cvetko, D.; Dell'Angela, M.; Floreano, L.; Cossaro, A., et al., Site-Specific Electronic and Geometric Interface Structure of Co-tetraphenyl-porphyrin Layers on Ag(111). Phys. Rev. B 2010, 81, 245403. 
30. Buchner, F.; Kellner, I.; Hieringer, W.; Görling, A.; Steinrück, H.-P.; Marbach, H., Ordering Aspects and Intramolecular Conformation of Tetraphenylporphyrins on $\operatorname{Ag}(111)$. Phys. Chem. Chem. Phys. 2010, 12, 13082-13090.

31. Wiengarten, A.; Lloyd, J. A.; Seufert, K.; Reichert, J.; Auwärter, W.; Han, R.; Duncan, D. A.; Allegretti, F.; Fischer, S.; Oh, S. C., et al., Surface-Assisted Cyclodehydrogenation; Break the Symmetry, Enhance the Selectivity. Chem. - Eur. J. 2015, $21,12285-12290$.

32. Di Santo, G.; Blankenburg, S.; Castellarin-Cudia, C.; Fanetti, M.; Borghetti, P.; Sangaletti, L.; Floreano, L.; Verdini, A.; Magnano, E.; Bondino, F., et al., Supramolecular Engineering through Temperature-Induced Chemical Modification of $2 \mathrm{H}$ Tetraphenylporphyrin on $\mathrm{Ag}(111)$ : Flat Phenyl Conformation and Possible Dehydrogenation Reactions. Chem. - Eur. J. 2011, 17, 14354-14359.

33. Diller, K.; Klappenberger, F.; Allegretti, F.; Papageorgiou, A. C.; Fischer, S.; Duncan, D. A.; Maurer, R. J.; Lloyd, J. A.; Oh, S. C.; Reuter, K., et al., Temperature-Dependent Templated Growth of Porphine Thin Films on the (111) Facets of Copper and Silver. $J$. Chem. Phys. 2014, 141, 144703.

34. Zhang, Y.-Q.; Kepčija, N.; Kleinschrodt, M.; Diller, K.; Fischer, S.; Papageorgiou, A. C.; Allegretti, F.; Björk, J.; Klyatskaya, S.; Klappenberger, F., et al., Homo-Coupling of Terminal Alkynes on a Noble Metal Surface. Nat. Commun. 2012, 3, 1286.

35. Wiengarten, A.; Seufert, K.; Auwärter, W.; Ecija, D.; Diller, K.; Allegretti, F.; Bischoff, F.; Fischer, S.; Duncan, D. A.; Papageorgiou, A. C., et al., Surface-Assisted Dehydrogenative Homocoupling of Porphine Molecules. J. Am. Chem. Soc. 2014, 136, 93469354. 
36. Diller, K.; Klappenberger, F.; Allegretti, F.; Papageorgiou, A. C.; Fischer, S.; Wiengarten, A.; Joshi, S.; Seufert, K.; Écija, D.; Auwärter, W., et al., Investigating the Molecule-Substrate Interaction of Prototypic Tetrapyrrole Compounds: Adsorption and SelfMetalation of Porphine on $\mathrm{Cu}(111)$. J. Chem. Phys. 2013, 138, 154710.

37. Krasnikov, S. A.; Sergeeva, N. N.; Brzhezinskaya, M. M.; Preobrajenski, A. B.; Sergeeva, Y. N.; Vinogradov, N. A.; Cafolla, A. A.; Senge, M. O.; Vinogradov, A. S., An XRay Absorption and Photoemission Study of the Electronic Structure of Ni Porphyrins and Ni N-Confused Porphyrin. J. Phys.: Condens. Matter 2008, 20, 235207.

38. Bischoff, F.; Seufert, K.; Auwärter, W.; Joshi, S.; Vijayaraghavan, S.; Écija, D.; Diller, K.; Papageorgiou, A. C.; Fischer, S.; Allegretti, F., et al., How Surface Bonding and Repulsive Interactions Cause Phase Transformations: Ordering of a Prototype Macrocyclic Compound on $\operatorname{Ag}(111)$. ACS Nano 2013, 7, 3139-3149.

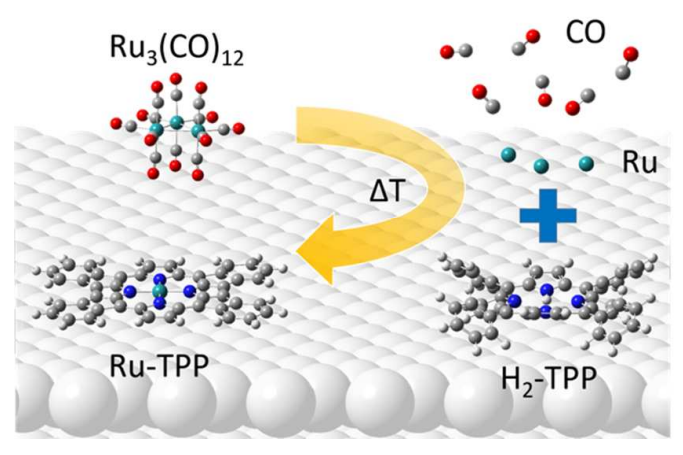

